\title{
Água residuária de esgoto doméstico tratado na atividade microbiana do solo e crescimento da mamoneira
}

\author{
Karine da S. Simões ${ }^{1}$, Maria de F. da S. P. Peixoto ${ }^{2}$, Ademir T. Almeida ${ }^{3}$, \\ Carlos A. da S. Ledo ${ }^{4}$, Clóvis P. Peixoto ${ }^{2} \&$ Francisco A. de C. Pereira ${ }^{2}$
}

\begin{abstract}
RESUMO
Os resíduos de esgoto doméstico apresentam teores de macro e micro nutrientes suficientes para atender a uma grande parte das culturas. Além de ser uma alternativa viável para aumentar a disponibilidade hídrica é uma forma efetiva de controle de poluição e preservação do meio ambiente. Neste contexto, realizou-se um experimento para avaliar a influência da aplicação de diferentes diluições de água residuária proveniente de esgoto doméstico tratado, na atividade microbiana de um Latossolo Amarelo Distrocoeso do Recôncavo Baiano e no crescimento inicial de plantas de mamoneira anã MPB 01. Avaliaram-se a atividade microbiana do solo e as características de crescimento da planta: altura, diâmetro do colo, biomassa seca da parte aérea, biomassa seca da raiz e volume de raízes. De acordo com os resultados, o efluente de esgoto doméstico tratado sem diluição estimula a atividade microbiana do Latossolo Amarelo Distrocoeso e prejudica o crescimento inicial da mamoneira anã MPB 01.
\end{abstract}

Palavras-chave: atributo biológico, efluente de esgoto doméstico, Ricinus communis L.

\section{Treated wastewater from domestic sewage on soil microbial activity and growth of castor bean}

\begin{abstract}
Wastewater from domestic sewage presents levels of macro and micro nutrients sufficient to support a large part of the crops. Besides being a viable alternative to increase water availability, it is an effective way to control pollution and preserve the environment. In this context, an experiment was carried out to evaluate the influence of applying different dilutions of treated wastewater from domestic sewage on the microbial activity of a distrophic cohesive yellow Latosol in the Recôncavo of Bahia. Its effect on early growth of dwarf castor bean plants MPB 01 were also evaluated. Soil microbial activity and growth characteristics such as plant height, stem diameter, shoot dry weight, root dry weight and root volume were evaluated. According to the results, the effluent of treated wastewater without dilution, stimulates microbial activity of distrophic cohesive yellow Latosol and impairs the early growth of dwarf castor bean MPB 01 .
\end{abstract}

Key words: biological attribute, effluent from treated domestic sewage, Ricinus communis L.

\footnotetext{
UFRB. Programa de Pós-graduação em Ciências Agrárias, Rua Rui Barbosa, 710, CEP 44380-000, Cruz das Almas, BA. Fone (75) 8226-6278. E-mail: karinesimoes01@hotmail.com

${ }^{2}$ Centro de Ciências Agrárias, Biológicas e Ambientais/UFRB. Fones (75) 9143-9422; (75) 9103-5858; (75) 3621-2798. E-mail: mfsppeixoto@gmail.com; cppeixot@gmail.com; fadriano64@gmail.com

${ }^{3}$ UFRB. Programa de Pós-graduação em Recursos Genéticos Vegetais. Fone (75) 8114-6656. E-mail: ademirtrindadeufrb@hotmail.com

${ }^{4}$ Embrapa Mandioca e Fruticultura. Rua Embrapa, s/n, C.P. 07, CEP 44380-000, Cruz das Almas, BA. Fone: (75) 3312-8061. E-mail: carlos.ledo@embrapa.br
} 


\section{INTRODUÇÃO}

No passado, o caminho mais fácil para a disposição de resíduos, tal como o das águas residuárias, eram os rios, lagos, mares ou recobrindo o solo sem as devidas considerações sobre as consequências de risco de saúde e dano ambiental. Porém esses métodos, altamente dependentes da renovação por processos naturais, tornaram-se inadequados mediante $o$ aumento populacional e industrial, associado à capacidade limitada assimilativa do ambiente e à escassez de recursos hídricos (Bouwer, 2000).

Visando diminuir os efeitos impactantes de suas atividades, o homem vem procurando adequar-se à nova realidade buscando tecnologias de menor custo para este fim. Dentre as tecnologias disponíveis para o tratamento de água residuária de origem doméstica ou destino final dos efluentes líquidos, destaca-se o método de disposição de água no solo cuja técnica vem sendo utilizada em grande escala em vários locais do mundo, sobretudo em regiões áridas e semiáridas (Medeiros, 2005).

Segundo Hoek et al. (2002) as maiores vantagens do aproveitamento da água residuária para fins agrícolas residem na conservação da água disponível e na possibilidade de aporte e reciclagem de nutrientes (reduzindo a necessidade de fertilizantes químicos), concorrendo para a preservação do meio ambiente. No entanto, apesar dos efluentes possuírem potencialidade de uso na agricultura há falta de tradição na sua reciclagem, principalmente no Brasil. Em consequência, existem poucas informações concernentes aos efeitos de sua disposição em solos com carga variável (solos tropicais). Deste modo, torna-se evidente a importância de estudar os efeitos decorrentes da disposição de efluente de esgoto tratado em solo tropical, no ambiente e nas plantas.

A mamoneira (Ricinus communis L.) é uma oleaginosa de elevada complexidade morfológica e fisiológica, com crescimento diferenciado em cada ramo, dicotômicos e heterogônicos, com cachos de várias idades fisiológicas, possuindo desenvolvimento heteroblástico e metabolismo fotossintético $\mathrm{C} 3$, tratando-se de uma planta rústica da família das Euforbiaceas, bastante tolerante à seca e exigente em radiação solar e luminosidade (Carvalho, 2005).

O cultivo de espécies oleaginosas constitui alternativa em apoio à agricultura familiar, criando melhores condições de vida em regiões carentes, valorizando potencialidades regionais e oferecendo alternativas a problemas econômicos e sócioambientais (Ramos et al., 2003). Apesar de considerada uma atividade de pequenos produtores, algumas ações do governo brasileiro vêm mudando este cenário. Através de estímulos para a cultura da mamona no Nordeste do Brasil, o governo pretende criar condições para o desenvolvimento da região. Nesta parte do Brasil há quase 4 milhões de ha com características edafoclimáticas apropriadas, em que se alcançaria o rendimento de até 1,5 t de sementes por hectare enquanto a média anual é de apenas $750 \mathrm{~kg}$ (Freitas \& Fredo, 2005).

Diante do exposto este trabalho tem como objetivo, avaliar a influência da aplicação de diferentes diluições de água residuária proveniente de esgoto doméstico tratado, na atividade microbiana de um Latossolo Amarelo Distrocoeso do Recôncavo Baiano e no crescimento inicial da mamoneira anã MPB 01, em condições de casa de vegetação.

\section{Material e Métodos}

O experimento foi conduzido em condições de casa de vegetação, no Campus da Universidade Federal do Recôncavo da Bahia, no município de Cruz das Almas. O solo utilizado no experimento, classificado como Latossolo Amarelo Distrocoeso, textura média a argilosa, foi coletado em uma área do Campo Experimental da Universidade Federal do Recôncavo da Bahia, na profundidade de $0-20 \mathrm{~cm}$. A adubação com nitrogênio, fósforo e potássio, foi feita com base no resultado das análises químicas do solo e de acordo com a recomendação de Carvalho (2005), para a cultura da mamona. Foram aplicados $50 \mathrm{~kg} \mathrm{ha}^{-1}$ de $\mathrm{N} ; 50 \mathrm{~kg} \mathrm{ha}^{-1} \mathrm{de}_{2} \mathrm{O}_{5}$ e $25 \mathrm{~kg} \mathrm{ha}^{-1}$ de $\mathrm{K}_{2} 0$. As fontes de $\mathrm{P}_{2} \mathrm{O}_{5}, \mathrm{~K}_{2} \mathrm{O}$ e N foram, respectivamente: superfosfato simples, cloreto de potássio e ureia (Tabela 1).

Tabela 1. Caracterização química da camada de 0-20 $\mathrm{cm}$ do Latossolo Amarelo distrocoeso, utilizado no experimento. Cruz das Almas, BA, setembro/outubro de 2010

\begin{tabular}{lc}
\hline \multicolumn{1}{c}{ Características } & Valor \\
$\mathrm{pH} \mathrm{H} \mathrm{H}_{2} \mathrm{O}(1: 2,5)$ & 4,9 \\
$\mathrm{H}+\mathrm{Al}\left(\mathrm{cmol}_{\mathrm{c}} \mathrm{dm}^{-3}\right)$ & 3,0 \\
$\mathrm{P}\left(\mathrm{mg} \mathrm{dm}^{-3}\right)$ & 16,0 \\
$\mathrm{M} .0\left(\mathrm{~g} \mathrm{~kg}^{-1}\right)$ & 10,7 \\
$\mathrm{~K}^{+}\left(\mathrm{cmol}_{\mathrm{c}} \mathrm{dm}^{-3}\right)$ & 0,12 \\
$\mathrm{Ca}^{+2}\left(\mathrm{cmol}_{\mathrm{c}} \mathrm{dm}^{-3}\right)$ & 1,2 \\
$\mathrm{Mg}^{+2}\left(\mathrm{cmol}_{\mathrm{c}} \mathrm{dm}^{-3}\right)$ & 0,6 \\
$\mathrm{Na}\left(\mathrm{cmol}_{\mathrm{c}} \mathrm{dm}^{-3}\right)$ & 0,1 \\
$\mathrm{SB}\left(\mathrm{cmol}_{\mathrm{c}} \mathrm{dm}^{-3}\right)$ & 2,2 \\
$\mathrm{~T}\left(\mathrm{cmol}_{\mathrm{c}} \mathrm{dm}^{-3}\right)$ & 5,0 \\
$\mathrm{~V}(\%)$ & 44,0 \\
$\mathrm{PST}(\%)$ & 2,0 \\
$\mathrm{RAS}\left(\mathrm{mmol} \mathrm{L}^{-1}\right)^{0,5}$ & 0,01 \\
$\mathrm{CE}$ & 0,12 \\
\hline
\end{tabular}

$\mathrm{H}+\mathrm{Al}-$ Acidez potencial; $\mathrm{P}$ - Fósforo disponível; M.O - Matéria orgânica; $\left(\mathrm{K}^{+}, \mathrm{Ca}^{+2} \mathrm{e} \mathrm{Mg}^{+2}\right)$ Potássio, Cálcio e Magnésio trocável, respectivamente; SB - Soma de bases trocáveis; CTC (T) - Capacidade de troca catiônica a pH 7,0; V - Índice de saturação de bases; PST - Percentagem de sódio trocável; RAS - Razão de adsorção de sódio; CE - Condutividade elétrica do solo

O município está situado no Recôncavo Baiano a $200 \mathrm{~m}$ de altitude, $12^{\circ} 40^{\prime} 19^{\prime \prime}$ de latitude sul e $39^{\circ} 06^{\prime} 22^{\prime \prime}$ de longitude a Oeste de Greenwich (Almeida, 1999).

O delineamento experimental foi inteiramente casualizado com 4 repetições e 5 tratamentos: água residuária com quatro diferentes proporções de diluição do efluente de esgoto doméstico tratado (EET): T1- 100\% EET; T2- 75\% EET + $25 \%$ água de poço (AP) ; T3- 50\% EET + 50\% AP; T4 - 25\% $\mathrm{EET}+75 \%$ AP e T5 - AP.

Utilizaram-se, no experimento, vasos de aproximadamente $5 \mathrm{~kg}$, em que cada vaso representou uma repetição. No plantio foram colocadas 3 sementes por cova efetuando-se o desbaste após 10 dias, deixando-se uma planta por vaso. O efluente líquido tratado foi armazenado em uma caixa de água e diluído com o auxílio de outras três caixas de água de igual volume, de forma a implementar os tratamentos T1, T2, T3 e T4.

Determinou-se a umidade correspondente à capacidade de campo do solo utilizando-se o método do torrão separado pela frente de molhamento, descrito por Costa (1983). A partir daí, o controle da irrigação foi baseado no peso inicial de cada vaso.

A água residuária utilizada para irrigação foi proveniente da estação de tratamento de esgoto doméstico, localizada na 
cidade de Cachoeira, BA, e operada pela Empresa Baiana de Águas e Saneamento S.A. (EMBASA).

As análises físico-químicas do efluente e da água de poço (Tabela 2) foram realizadas no Laboratório de Qualidade da Água do Departamento de Engenharia Agrícola e Ambiental Universidade Federal de Viçosa (DEAA/UFV) e no Laboratório da Comissão Executiva do Plano da Lavoura Cacaueira Ministério da Agricultura Pecuária e Abastecimento (CEPLAC/ MAPA), seguindo a metodologia proposta pela APHA (1995).

Tabela 2. Caracterização físico-química do efluente de esgoto doméstico tratado (EET) e da água de poço (AP) utilizados no experimento

\begin{tabular}{|c|c|c|c|}
\hline Constituintes & Unidades & AP & EET \\
\hline $\mathrm{pH}$ & & 8,2 & 6,5 \\
\hline $\mathrm{Ca}$ & $\mathrm{mg} \mathrm{L}^{-1}$ & 169,94 & 86,57 \\
\hline $\mathrm{Mg}$ & $\mathrm{mg} \mathrm{L}^{-1}$ & 222,77 & 78,8 \\
\hline K & $\mathrm{mg} \mathrm{L}^{-1}$ & 16 & 51 \\
\hline $\mathrm{Na}$ & $\mathrm{mg} \mathrm{L}^{-1}$ & 56 & 140 \\
\hline C.E & $\mathrm{dS} \mathrm{m}^{-1}$ & 1,42 & 2,92 \\
\hline$P$ & $\mathrm{mg} \mathrm{L}^{-1}$ & 0,10 & 15,9 \\
\hline $\mathrm{N}$ & $\mathrm{mg} \mathrm{L}^{-1}$ & 24,9 & 60 \\
\hline $\mathrm{Cl}^{-}$ & $\mathrm{mg} \mathrm{L}^{-1}$ & 812,98 & 48 \\
\hline $\mathrm{HCO}_{3}^{-}$ & $\mathrm{mg} \mathrm{L}^{-1}$ & 922,47 & 1698,52 \\
\hline STD & $\mathrm{mg} \mathrm{L}^{-1}$ & 1050,8 & 2160,8 \\
\hline DBO & $\mathrm{mg} \mathrm{L}^{-1}$ & 6,7 & 155 \\
\hline DQO & $\mathrm{mg} \mathrm{L}^{-1}$ & 10 & 269 \\
\hline $\mathrm{CO}$ & $\mathrm{mg} \mathrm{L}^{-1}$ & 46 & 138 \\
\hline CT & NMP $100 \mathrm{~mL}^{-1}$ & $1,5 \times 10^{2}$ & $1,3 \times 10^{6}$ \\
\hline $\mathrm{CF}$ & NMP $100 \mathrm{~mL}^{-1}$ & $<1,0$ & $<1,0$ \\
\hline RAS & $\left(\mathrm{mmol} \mathrm{L}^{-1}\right)^{0,5}$ & 1,38 & 4,48 \\
\hline Relação Ca:Mg & & 0,76 & 1,10 \\
\hline Relação DBO:DQO & & 0,65 & 0,58 \\
\hline
\end{tabular}

DQO - demanda química de oxigênio; DBO - demanda bioquímica de oxigênio; CO - carbono orgânico; CT - coliformes totais; CF - coliformes termo tolerantes (Fecais - E. coli); C.E condutividade elétrica; STD - Sólidos totais dissolvidos

A atividade microbiana (respiração basal) foi avaliada ao final do ensaio, pela quantificação do dióxido de carbono $\left(\mathrm{CO}_{2}\right)$ liberado pelo processo de respiração microbiana, durante três dias de incubação em temperatura ambiente (em torno de 25 ${ }^{\circ} \mathrm{C}$ ), de acordo com a metodologia descrita por Alef (1995).

Ao final do ensaio (45 dias), foi avaliado o crescimento inicial das plantas, determinando-se a produção de biomassa seca da parte aérea e a biomassa seca da raiz utilizando-se uma estufa de circulação forçada, em que o material vegetal ficou durante $72 \mathrm{~h}$ a uma temperatura de aproximadamente $65^{\circ} \mathrm{C}$ (Peixoto et al., 2010). Foram determinados a altura da planta, o diâmetro do colo e o volume de raízes. O volume de raízes foi determinado com auxílio de uma proveta graduada de 100 $\mathrm{mL}$, mais água da torneira; após completar o volume da proveta com água fez-se a imersão da raiz, previamente lavada e secada. Com uma pipeta graduada de $5 \mathrm{~mL}$, retirou-se e se anotou o excesso de água que ultrapassou a capacidade da proveta, o qual correspondia ao volume da raiz, considerando-se que: 1 $\mathrm{mL}=1 \mathrm{~cm}^{3}$ (Peixoto et al., 2010).

Os dados obtidos foram submetidos à análise de variância da regressão, com auxilio do software SISVAR .

\section{Resultados E Discussão}

A atividade microbiana (liberação de $\mathrm{CO}_{2}$ ) aumentou com a aplicação de concentrações crescentes do efluente de esgoto doméstico tratado com o menor valor para o tratamento testemunha (100\% de água de poço) (Figura 1). Este resultado está de acordo com o encontrado por Sparling et al. (2006) ao verificarem aumento da atividade microbiana ao longo do tempo, em função da irrigação com efluente de esgoto doméstico tratado em quatro solos da Nova Zelândia.

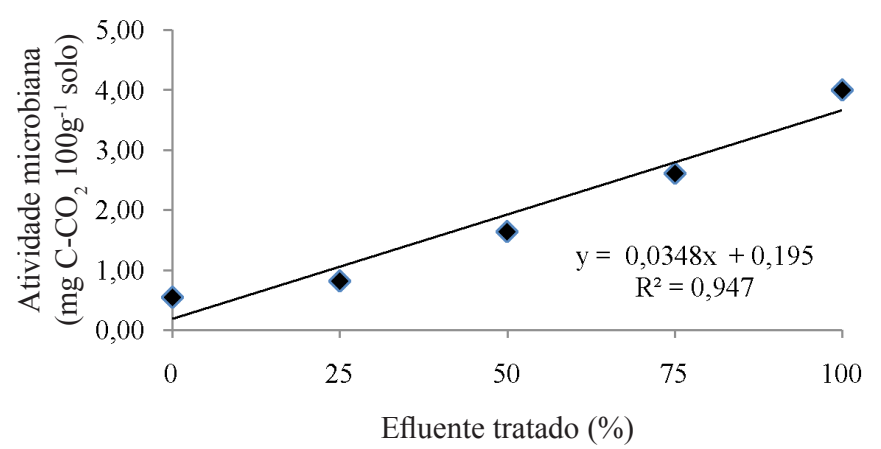

Figura 1. Atividade microbiana (mg C- $\left.-\mathrm{CO}_{2} 100 \mathrm{~g} \mathrm{solo}^{-1}\right)$ do solo em diferentes diluições de água residuária de efluente de esgoto doméstico tratado. T1 (100\% do efluente tratado); T2 (75\% do efluente tratado); T3 (50\% do efluente tratado); T4 ( $25 \%$ do efluente tratado); T5 (100\% de água de poço)

Verifica-se que no tratamento testemunha ocorreu menor atividade microbiana devido, possivelmente, ao baixo teor de matéria orgânica $\left(10,07 \mathrm{~g} \mathrm{~kg}^{-1}\right)$ do Latossolo Amarelo Distrocoeso (Tabela 1).

Na Tabela 3 se encontra o resumo da análise de variância da característica de crescimento e a atividade microbiana da mamoneira. Verifica-se, através dos dados obtidos, que a atividade microbiana foi significativamente influenciada pela aplicação do efluente de esgoto doméstico tratado no Latossolo Amarelo Distrocoeso, porém sua aplicação não favoreceu o crescimento inicial da mamoneira anã MPB 01. O resultado

Tabela 3. Resumo da análise de variância da altura da planta - AP $(\mathrm{cm})$, diâmetro do colo - DCOL $(\mathrm{cm})$, massa seca da raiz - MSR (g planta-1 ${ }^{-1}$, volume da raiz - VR, massa seca da parte aérea - MSPA (g planta-1) e atividade microbiana (AM) em função das diluições de água residuária de efluente de esgoto doméstico

\begin{tabular}{|c|c|c|c|c|c|c|c|}
\hline \multirow{2}{*}{ FV } & \multirow{2}{*}{ GL } & \multicolumn{5}{|c|}{ QM } & \multirow[b]{2}{*}{ AM } \\
\hline & & AP & DCOL & MSR & VR & MSPA & \\
\hline Resíduo & 3 & $82,14^{\text {ns }}$ & $0,00^{\text {ns }}$ & $0,08^{n s}$ & $3,17^{\text {ns }}$ & $0,63^{\text {ns }}$ & $7,51^{\star *}$ \\
\hline Resíduo convencional & 1 & $514,10^{* *}$ & $0,17^{\star \star}$ & $4,94^{\star \star}$ & $80,00^{* \star}$ & 16,84 ** & $9,42^{* *}$ \\
\hline Erro & 15 & 51,89 & 0,00 & 0,01 & 2,42 & 0,33 & 0,21 \\
\hline CV (\%) & & 17,67 & 6,96 & 22,05 & 15,17 & 16,69 & 23,64 \\
\hline Média geral & & 40,76 & 0,76 & 1,42 & 10,25 & 3,46 & 1,93 \\
\hline
\end{tabular}

${ }^{* *} \mathrm{e}^{*}$ significativo a 0,01 e 0,05 de probabilidade, respectivamente, pelo teste de $\mathrm{F}$. ns não significativo a 0,05 de probabilidade 
encontrado se diferencia do estudado por Xavier et al. (2009) ao observarem interações significativas para as variáveis altura de plantas e diâmetro caulinar denotando a interdependência entre eles, o que foi refletido no crescimento das plantas. Para Lima et al. (2005) a aplicação de água residuária de esgoto doméstico tratado como suplemento nutricional para a cultura da mamoneira é uma estratégia viável para o aproveitamento deste resíduo, haja vista que, na medida em que as cidades vão investindo no tratamento do esgoto doméstico, quantidades cada vez maiores de resíduo de esgoto ou biossólidos são disponibilizadas com grande potencial de uso agrícola e redução de custo de produção.

Finocchiaro \& Kremer (2010) verificaram uma relação inversa entre a atividade microbiana do solo e a deposição de efluente de esgoto doméstico tratado quando comparado com a água de rio embora tenham observado que as águas residuais tinham duas vezes a condutividade elétrica e quatro vezes a concentração de sódio, comparadas com a água do rio. Neste trabalho a condutividade elétrica de $2,92 \mathrm{dS} \mathrm{m}^{-1}$ do resíduo utilizado estimula a atividade microbiana do solo.

Considerando que a maioria dos micro-organismos do solo é heterotrófica, o aporte de fontes de carbono ao solo promove um aumento da população microbiana em função da disponibilidade de substrato a ser decomposto.

Em sua composição, o EET contém $138 \mathrm{mg} \mathrm{L}^{-1}$ de carbono orgânico, $60 \mathrm{mg} \mathrm{L}^{-1}$ de nitrogênio, $15,9 \mathrm{mg} \mathrm{L}^{-1}$ de fósforo, $51 \mathrm{mg} \mathrm{L}^{-1}$ de potássio, 86,57 $\mathrm{mg} \mathrm{L}^{-1}$ de cálcio 78,8 $\mathrm{mg} \mathrm{L}^{-1}$ de magnésio (Tabela 2) nutrientes utilizados pelos microorganismos do solo. É provável que este fato explique a maior atividade microbiana do Latossolo Amarelo Distrocoeso quando se aplicou o efluente de esgoto doméstico tratado. Hawko \& Summers (2006) e Friedel et al. (2000), também verificaram incremento da atividade microbiana do solo em função do aumento das concentrações de carbono orgânico e nitrogênio total no solo.

Com relação à altura das plantas (Figura 2A) observa-se, em função do aumento das diluições do EET, uma amplitude de 50 $\mathrm{cm}(0 \%$ do efluente $)$ e $35 \mathrm{~cm}$ ( $100 \%$ do efluente) em que a altura de planta foi reduzida linearmente na medida em que aumentava a proporção do efluente. Lima et al. (2005) constataram que o aumento das doses do resíduo de esgoto propiciou maior crescimento das mudas de mamoneira avaliadas aos 42 dias após a emergência ( DAE). Rodrigues et al. (2009) também constataram, utilizando água residuária, que após os $40 \mathrm{DAE}$ houve um crescimento melhor da mamoneira com a aplicação do resíduo, assim como Souza et al. (2010) observaram que a mamoneira apresentou crescimento exponencial independente do tratamento aplicado com o esgoto doméstico tratado.

Verificou-se redução: do diâmetro do colo da planta, da produção de biomassa seca da parte aérea, das raízes e no volume de raiz (Figuras 2B, 2C, 2D e 2E, respectivamente), com a aplicação de doses crescentes do EET no solo no entanto, em escala polinomial do segundo grau com uma queda mais pronunciada entre o tratamento testemunha ( $0 \%$ do EET) e $25 \%$ de EET; a partir daí houve tendência de estabilização da curva.

Nascimento et al. (2006), têm mostrado um incremento no crescimento de plantas de mamoneira em função da aplicação de água residuária de esgoto doméstico tratado no solo, da
A.

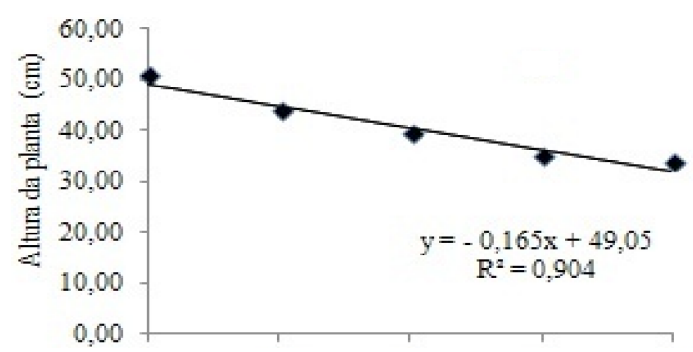

B.

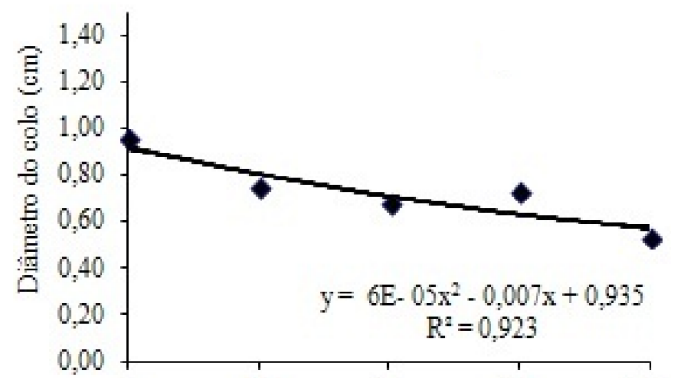

C.

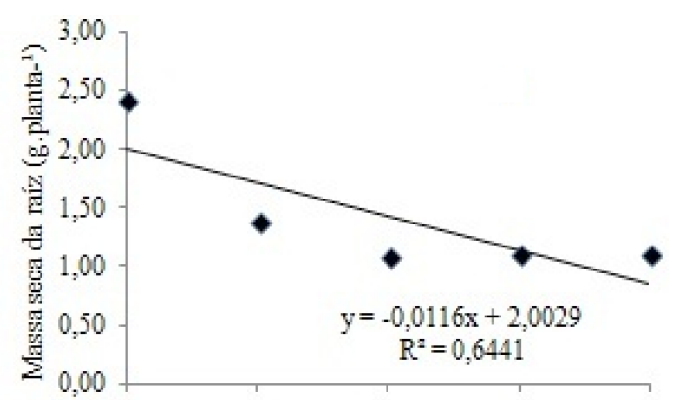

D.

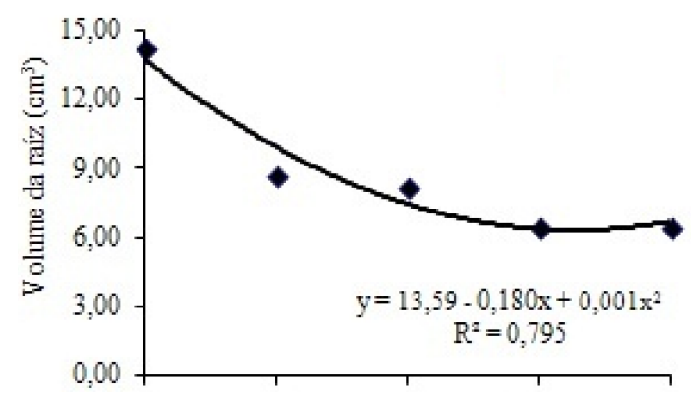

E.

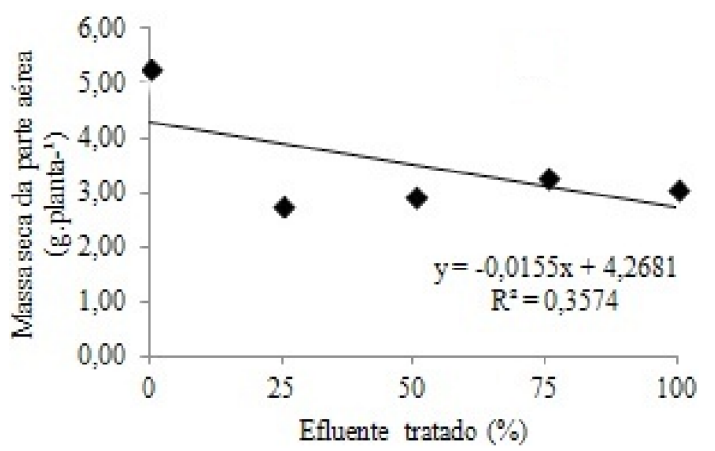

T1 (100\% do efluente tratado); T2 (75\% do efluente tratado); T3 (50\% do efluente tratado); T4 ( $25 \%$ do efluente tratado); T5 (100\% de água de poço)

Figura 2. Altura da planta $(\mathrm{cm})(\mathrm{A})$, Diâmetro do colo $(\mathrm{cm})(\mathrm{B})$, Massa seca da raiz $\left(\mathrm{g} \mathrm{planta}^{-1}\right)(\mathrm{C})$, Volume da raiz $\left(\mathrm{cm}^{3}\right)(\mathrm{D})$, Massa seca da parte aérea $\left(\mathrm{g} \mathrm{planta}^{-1}\right)(\mathrm{E})$ em função das diluições de água residuária de efluente de esgoto doméstico tratado 
mesma forma que Cavallet et al. (2006) observaram, ao estudar o efeito da utilização de água residuária no solo, melhoria da fertilidade do solo e um incremento na produção de grãos de milho em todos os tratamentos aos quais se aplicou a água residuária devido à presença de nutrientes. Silva et al. (2007) avaliaram a adubação com macro e micronutrientes na cultura da mamona e concluíram que a adubação promoveu aumento de produtividade da cultivar BRS Nordestina, com destaque para a adubação nitrogenada; apesar disto, o crescimento inicial da mamoneira MPB01 foi prejudicado neste trabalho.

De acordo com a Tabela 2, o efluente aplicado tem um teor de sódio de $140 \mathrm{mg} \mathrm{L}^{-1}$ teor este três vezes maior que o da água do poço $56 \mathrm{mg} \mathrm{L}^{-1}$. Sem dúvida essa alta concentração de sódio presente no EET é que está acarretando redução na análise de crescimento da mamoneira considerando-se, embora de maneira indireta, uma RAS (razão de adsorção de sódio), de 4,48 (meq L $\left.\mathrm{L}^{-1}\right)^{0,5}$ do EET em relação a 1,38 (meq $\left.\mathrm{L}^{-1}\right)^{0,5}$ da água do poço, caracterizando um aumento da PST (Percentagem de Sódio Trocável) no complexo de troca do solo aumentando, assim, o efeito nocivo do sódio à cultura. Severino et al. (2006) constataram que a irrigação diária com água residuária em mamoneira estimulou o desenvolvimento vegetativo apesar dos sais presentes na água de irrigação. Já com a condutividade elétrica de $2,92 \mathrm{dS} \mathrm{m}^{-1}$ e considerando que a mamoneira é muito sensível à salinidade, possivelmente foi um dos fatores que contribuíram para prejudicar o crescimento da mamoneira neste estudo. Referidos resultados concordam com Silva et al. (2008) que, analisando o desenvolvimento e a produção de duas cultivares de mamoneira sob estresse salino submetido a quatro níveis de C.E da água de irrigação (entre 0,7 a $6,7 \mathrm{dS} \mathrm{m}^{-1}$ ), verificaram reduções lineares entre os valores de altura de plantas e diâmetro do caule, para as cultivares de BRS Paraguaçu e BRS Energia.

Lima et al. (2007) constataram, estudando a influência da salinidade na cultivar BRS 149-Nordestina, que a mesma foi sensível à presença de sais na água de irrigação com tendência a diminuir o crescimento vegetativo com o aumento da salinidade da água de irrigação.

\section{Conclusão}

O efluente de esgoto doméstico tratado estimula a atividade microbiana do Latossolo Amarelo distrocoeso e prejudica o crescimento inicial da mamoneira anã MPB01.

\section{Literatura Citada}

Alef, K. Estimation of soil respiration. In: Alef, K.; Nannipieri, P. (ed.). Methods in applied soil microbiology and biochemistry. London: Academic Press, 1995. 576p.

Almeida, O. A. Informações meteorológicas do CNP: Mandioca e Fruticultura Tropical. Cruz das Almas: Embrapa CNPMF. 1999. 35p.

APHA - American Public Health Association. Standard methods. 19.ed., Washington: APHA, 1995. 46p.

Bouwer, H. Integrated water management: Emerging issues and challenges. Agricultural Water Management, v.45, p.217-28, 2000 .
Carvalho, B. C. L. Manual do cultivo da mamona. Salvador: EBDA, 2005. 65p.

Cavallet, L. E.; Lucchesi, L. A. C.; Moraes, A. de M.; Schimidt, E.; Perondi, M. A.; da Fonseca, R. A. Melhoria da fertilidade do solo decorrentes da adição de água residuária da indústria de enzimas. Revista Brasileira de Engenharia Agrícola e Ambiental, v.10, p.724-729, 2006.

Costa, M. P. Efeito da matéria orgânica em alguns atributos do solo. Piracicaba: ESALQ/USP, 1983. 137p. Dissertação Mestrado

Finocchiaro, R. G.; Kremer, R. J. Effect of municipal wastewater as a wetland water source on soil microbial activity. Communications in Soil Science and Plant Analysis, v.4, p.1974-1985. 2010.

Freitas, S. M. de.; Fredo. C. E. Biodiesel à base de óleo de mamona: algumas considerações. Revista Informações Econômicas,v.35, p.37-42, 2005.

Friedel, J. K.; Langanger, T.; Siebe, C.; Stahr, K. Effects of longterm waste water irrigation on soil organic matter, soil microbial biomass and its activities in central Mexico. Biology and Fertility of Soils, v.31, p.414-421, 2000.

Hawko, R. M.; Summes, S. A.; Effects of land application of farm dairy effluent on soil properties: A litersture rewiew. New Zealand Journal of Agricultural Research, v.49, p.307320, 2006.

Hoek, W. van de; Hassan, U. M.; Ensink, J. H. J.; Feenstra, S.; Raschid-Sally,L.; Munir, S.; Aslam, R.; Alim, N.; Hussain, R.; Matsuno, Y. Urban wastewater: a valuable resource for agriculture. A case study from Horoonabad, Pakistan. Colombo: International Water Management Institute, 2002. 29p.

Lima, C. B.; Santos Filho, S. V. dos; Santos, M. A.; Oliveira, M. de. Influência da água salina nas características físicoquímicas do solo e no desenvolvimento da mamoneira cultivada em vasos. Caatinga, v.20, p.132-136, 2007.

Lima, R. de L. S. de; Severino, L. S.; Silva, M. I. L.; Vale, L. S.; Beltrão, N. E. de M. Crescimento inicial de mudas de mamoneira em substrato contendo lodo de esgoto e casca de amendoim. Revista de Oleaginosas e Fibrosas, v.9, p.887-891, 2005.

Medeiros, S. S. Alterações físicas e químicas do solo e estado nutricional do cafeeiro em resposta à fertirrigação com água residuária de origem doméstica. Viçosa: UFV, 2005. 114p. Tese Doutorado

Nascimento, M. B. H. do; Lima, V. L .A. de; Beltrão, N. E. de M.; Souza, A. P.; Figueiredo, I. C. de. M.; Lima, M. M. de. Uso de biossólido e de água residuária no crescimento e desenvolvimento da mamona. Revista Brasileira Oleaginosas e Fibrosas, v.10, p.1001-1007, 2006.

Peixoto, M. F. S. P.; Borges, V. P; Borges, V. P.; Peixoto, C. P.Ação do triluralin na micorrização e crescimento de plantas de amendoim (Arachis hypogaea). Planta Daninha, v.28, p.609-614, 2010.

Ramos, L. P.; Kucek, K. T.; Domingos, A. K.; Wilheim, H. M. Biodiesel: Um Projeto de sustentabilidade econômica e socioambiental para o Brasil. Revista Biotecnologia, Ciência e Desenvolvimento, v.31, p.28-37, 2003. 
Rodrigues, L. N.; Nery, A. R.; Fernandes, P. D.; Beltrão, N. E. de M., Gheyi, R. H. Crescimento e produção de bagas da mamoneira irrigada com água residuária doméstica. Revista Brasileira de Engenharia Agrícola e Ambiental, v.13, p.825-835, 2009.

Severino, L. S.; Ferreira, G. B.; Moraes, C. T. de A.; Gondim, T. M. de S.; Freire, S. de A.; Castro, D. A. de.; Cardoso, G. D.; Beltrão, N. E. de M. Crescimento e produtividade da mamoneira adubada com macronutrientes e micronutrientes. Pesquisa Agropecuária Brasileira, v.41, p.563-568, 2006.

Silva, S. M. S.; Alves, A. N.; Gheyi, H. R.; Beltrão, N. E. de M.; Severino, L. S.; Soares, F. A. L. Desenvolvimento e produção de duas cultivares de mamoneira sob estresse salino. Revista Brasileira de Engenharia Agrícola e Ambiental, v.12, p.335-342, 2008.
Silva, T. R. B. da; Leite, V. E.; Silva, A. R. B. da; Viana, L. H. Adubação nitrogenada em cobertura na cultura da mamona em plantio direto. Pesquisa Agropecuária Brasileira, v.42, p.1357-1359, 2007.

Souza, N. C. de.; Mota, S. B.; Bezerra, F. M. L.; Aquino, B. B. F. de.; Santos, A. B. dos. Produtividade da mamona irrigada com esgoto doméstico tratado. Revista Brasileira de Engenharia Agrícola e Ambiental v.14, p.478-484, 2010.

Sparling, G. P.; Barton, L.; Duncan, L.; Mcgill, A.; Speir, T. W.; Schipper, L. A.; Arnold, G.; Schaik, A. Van. Nutrient leaching and changes in soil characteristics of four contrasting soils irrigated with secondary-treated municipal wastewater for four years. Australian Journal of Soil Research, v.44, p.107-116, 2006. Xavier, J. F.; Azevedo, C. A. V.; Beltrão, N. E. M.; Andrade, A. R. S.; Lima, V. L. A. Crescimento da mamoneira sob diferentes tipos de águas residuárias e níveis de água no solo. Ambi-Agua, v.4, p.196-210, 2009. 